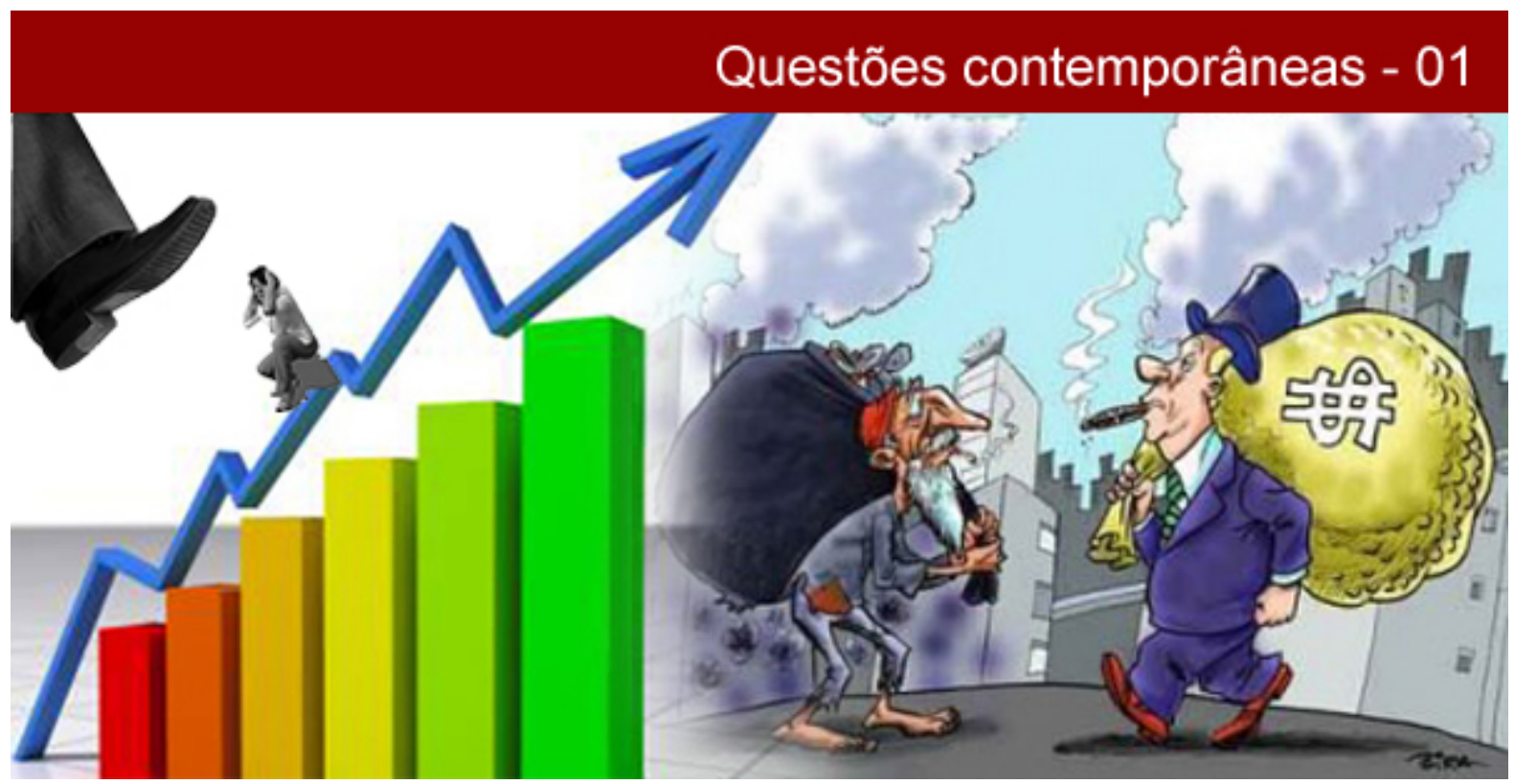

\title{
O NOVO DESENVOLVIMENTISMO E A QUESTÃO SOCIAL NA ATUALIDADE
}

\section{Leonardo de Araújo e Mota}

Doutor em Sociologia pela Universidade Federal do Ceará (UFC). Professor do Departamento de Filosofia e Ciências Sociais (DFCS) e do Programa de Pós-Graduação em Desenvolvimento Regional (PPGDR) da Universidade Estadual da Paraíba (UEPB).E-mail: la-mota@uol.com.br.

Resumo: No início do século XXI, vários líderes de esquerda latino americanos são eleitos para presidente da república, utilizando um discurso que rejeita os cânones neoliberais. Entendeu-se, então, que iria proceder-se uma virada de volta ao Estado como interventor na economia e promotor da justiça social. Neste prisma, a retórica do desenvolvimentismo retorna à pauta das discussões políticas e econômicas através do Novo Desenvolvimentismo. A questão social agora seria equacionada por intermédio de um "pacto social" que contemplasse bons índices de competitividade, crédito acessível e políticas sociais de enfrentamento da pobreza. Entretanto, muitos teóricos diagnosticam que as políticas do Novo Desenvolvimentismo constituem mera falácia, tendo em vista que nosso cenário macroeconômico permanece atrelado ao neoliberalismo. O objetivo deste artigo foi realizar uma análise de conjuntura, empregando o conceito de Novo Desenvolvimentismo como chave analítica e utilizando a pesquisa bibliográfica como método de investigação. Concluiu-se que, embora a América Latina seja atualmente governada por partidos de orientação de esquerda que conseguiram incluir grandes contingentes populacionais no mercado de consumo e crédito, as empresas transnacionais continuam a degradar o meio ambiente, os direitos trabalhistas enfrentam contínuas ameaças e as políticas públicas tendem a centrar-se no enfrentamento da pobreza, fazendo com que o Estado incentive a ideologia do empreendedorismo e dos negócios para enfrentar as agruras do capitalismo contemporâneo em seu cenário de crise.

Palavras-chave: Desenvolvimento. Novo desenvolvimentismo. Questão Social.

\section{NEW DEVELOPMENTALISM AND SOCIAL ISSUES IN NOWADAYS}

Abstract: In the early twenty-first century, several Latin American leftist leaders are elected for president, using a discourse that rejects neoliberal economics. It was understood then that would happen a turn back to the state as intervening in the economy and promoting social justice. By the way, the rhetoric of developmentalism returns to the agenda of political and economic discussions through the New Developmentalism. The social issues now would be equated by means of a "social pact" that considers competitiveness, affordable credit and

\section{POLÊM!CA | Revista Eletronica da ver}


social policies addressing poverty. However, many theorists diagnose that the New Developmentalism policies are mere fallacy, given that our macroeconomic scenario remains linked to neoliberalism. The aim of this paper was to conduct a social analysis, employing the concept of New Developmentalism as an analytical key and using bibliographic research methods. It was concluded that, although Latin America is currently governed by left-wing parties that had include large populations in consumption and credit market, transnational companies continue to damage the environment, labor rights faces continuous threats and public policies tend to focus on the fight against poverty. So, the State continues to encourage the ideology of entrepreneurship and business to face the hardships of contemporary capitalism in its crisis scenario.

Keywords: Development. New Developmentalism. Social Issues.

\section{Introdução}

Hoje existe um reconhecimento por parte de vários teóricos de que o crescimento econômico não é sinônimo de desenvolvimento. Para que haja desenvolvimento é preciso algo mais que bons resultados econômicos, pois outras dimensões da vida humana, social e ambiental devem ser consideradas. Quando a noção de desenvolvimento é considerada apenas em sua vertente econômica, ou seja, quando os lucros são mais importantes que os cidadãos, vários conflitos passam a permear o tecido social, como ocorreu nas décadas em que as políticas neoliberais tornaram-se hegemônicas, principalmente nas economias latino americanas (BRAND; SECKLER, 2010). Entretanto, apesar de especialistas e políticos na América Latina terem criticado amplamente o modelo neoliberal e passado a adotar políticas econômicas que poderiam ser denominadas de pós-neoliberais, muitas das antigas práticas inerentes ao neoliberalismo ainda continuam a ser adotadas na prática.

O presente artigo tem como objetivo efetuar uma análise de conjuntura (SOUZA, 2014) acerca das propostas do Novo-desenvolvimentismo, uma vez que procurar demonstrar que, embora este novo modelo de desenvolvimento, em sua retórica, defenda o rompimento com o neoliberalismo e o retorno à intervenção do Estado na economia anunciando um horizonte de desenvolvimento econômico com justiça social, ele aprofunda a intensidade e exploração do trabalho, a mercantilização dos recursos naturais e minerais, a cooptação dos movimentos sociais, a financeirização da economia e o consentimento das massas despolitizadas por intermédio de políticas compensatórias de transferência de renda, fatores que tornam inviável um desenvolvimento baseado na ampliação dos direitos sociais universais, na politização das classes subalternas e preservação do meio ambiente (CASTELO BRANCO, 2009; MOTA, AMARAL, PELLUZO, 2012; SAMPAIO JR., 2012).

\section{Do antigo ao novo desenvolvimentismo}

\section{POLÊM!CA | Revista Eletronica da verj}


A partir dos anos 1930 ou, ao menos, após os anos 1950 até meados da década de 1970, muitos países latino-americanos, incluindo o Brasil, desenvolveram uma estratégia nacional de desenvolvimento que ficou conhecida como Nacional Desenvolvimentismo. A intenção era reduzir as relações de dependência dos produtos manufaturados provenientes dos países mais desenvolvidos (substituição de importações), como também atenuar as fontes de “atraso social” com o predomínio do grande latifúndio, a pobreza e a grande concentração de renda no campo e nas metrópoles (reformas de base). Acreditava-se que o Estado deveria fazer investimentos diretos em infraestrutura e em algumas indústrias. O nacionalismo e o Estado como propulsor desse projeto eram fundamentais para seu êxito, visto que:

\begin{abstract}
“(...) o objetivo básico da política era promover o desenvolvimento econômico e, em segundo lugar, para que isso acontecesse, a nação - ou seja, os empresários, a burocracia do Estado, as classes médias e os trabalhadores unidos na competição internacional - precisava definir os meios para alcançar esse objetivo no âmbito do sistema capitalista, tendo o Estado como o principal instrumento de ação coletiva" (BRESSER-PEREIRA, 2014, p. 32).
\end{abstract}

Tal modelo de gestão da economia política atravessou vários governos, tanto democráticos, quanto autoritários. A partir da década de 1980, porém, a economia brasileira passou a vivenciar vários ciclos de estagnação, alta inflação e aumento da dívida externa. Esse período ficou conhecido como a “década perdida”, que resultou em vários planos econômicos fracassados que corroíam cada vez mais os salários dos trabalhadores, aumentando as desigualdades sociais.

A estabilidade econômica (controle da inflação) viria apenas após o Plano Real, ao mesmo tempo em que o Brasil se alinhava com as diretrizes do Consenso de Washington, adotando o receituário do Fundo Monetário Internacional e do Banco Mundial, instituições fortemente influenciadas pela ortodoxia monetária estadunidense. Tal período, circunscrito na década de 1990, foi caracterizado pelo fim da onda de “estatismo”, característico da "Era Vargas”, que guiara anteriormente a economia e posicionou, em seu lugar, o mercado como propulsor do desenvolvimento econômico e social; a denominada onda neoliberal.

O neoliberalismo, através da imposição dos mecanismos de mercado como uma tentativa de reversão da crise do capital iniciada nos anos 1970 impõe várias políticas de privatizações e de ajuste estrutural, resultando na depreciação da coisa pública e no estrangulamento do Welfare State em vários países. No caso brasileiro, no qual o Estado do Bem Estar Social sequer tinha se consolidado nos moldes dos países mais desenvolvidos, os 
problemas sociais foram remetidos às Organizações Não-Governamentais (ONGs) e não mais ao Estado ou ao ideal de um "projeto nacional” unificado, como ocorrera no caso do Nacional Desenvolvimentismo. Dessa forma, a ideologia da competência inerente ao neoliberalismo, cindiu a sociedade entre perdedores e vencedores, resultando em "uma formidável insegurança, um sentimento de abatimento, primeiro entre os trabalhadores braçais, mas também na pequena burguesia” (BOURDIEU, 1998, p. 51).

Posteriormente, sobretudo após os efeitos da crise econômica mundial de 2008, que afetou a economia de vários países, o Estado brasileiro realiza uma série de ações na área econômica com o objetivo de reduzir as disparidades sociais mantendo a competitividade através de um novo modelo de desenvolvimento (Novo Desenvolvimentismo), em uma tentativa de conciliar as leis de mercado com justiça social, embora se distanciando do antigo desenvolvimentismo brasileiro, conforme tabela a seguir:

\begin{tabular}{|c|c|}
\hline Antigo desenvolvimentismo & Novo desenvolvimentismo \\
\hline $\begin{array}{l}\text { 1. A industrialização é baseada na } \\
\text { substituição de importações. }\end{array}$ & $\begin{array}{l}\text { 1. Crescimento baseado na exportação } \\
\text { combinada com um mercado interno } \\
\text { forte. }\end{array}$ \\
\hline $\begin{array}{l}\text { 2. O Estado tem um papel central } \\
\text { na obtenção de poupança } \\
\text { forçada e na realização de } \\
\text { investimentos. }\end{array}$ & $\begin{array}{l}\text { 2. O Estado deve criar oportunidades de } \\
\text { investimento e reduzir as } \\
\text { desigualdades econômicas. }\end{array}$ \\
\hline 3. A política industrial é central. & 3. A política industrial é subsidiária. \\
\hline 4. Atitude mista em relação aos \\
déficits orçamentários.
\end{tabular}

Fonte: BRESSER-PEREIRA, 2014.

No início do século XXI, uma série de líderes políticos de esquerda latino americanos, como Hugo Chávez (Venezuela), Michele Bachelet (Chile), Nestor Kirchner (Argentina) e Luís Inácio Lula da Silva (Brasil), são eleitos com um claro discurso de combate ao 
neoliberalismo e prometendo um retorno do Estado como interventor privilegiado na "questão social”. A partir disso é que a retórica do desenvolvimentismo retorna à pauta das discussões acadêmicas e também das políticas públicas engendradas por esses governos. Conforme salienta Castelo Branco (2009), o objetivo dos novos desenvolvimentistas no Brasil seria:

“(...) entrar, como uma espécie de Terceira Via, na disputa pela hegemonia ideopolítica para a consolidação de uma estratégia de desenvolvimento alternativa aos modelos em vigência na América do Sul, tanto ao "populismo burocrático", representado pelos setores arcaicos da esquerda e partidários do socialismo, quanto à ortodoxia convencional, representada por elites rentistas e defensores do neoliberalismo”. (p. 74)

Mais adiante, o mesmo autor resume as principais premissas deste novo modelo de desenvolvimento:

\begin{abstract}
"Em síntese, o Estado deve garantir condições macroeconômicas e salvaguardas jurídicas que reduzam a incerteza do ambiente econômico, propiciando um horizonte mais previsível do cálculo de risco do investimento privado, e aumentando, por sua vez, a demanda por fatores de produção, o emprego e os ganhos dos trabalhadores. Assim, o Brasil reduzirá a pobreza e a desigualdade social. O projeto novodesenvolvimentista de intervenção na “questão social”, portanto, baseia-se no crescimento econômico e na promoção da equidade social via a igualdade de oportunidades. Esta é, grosso modo, a utopia da intelligentsia novodesenvolvimentista”. (Ibidem, p. 78, grifo do autor)
\end{abstract}

Dessa forma, agora a questão social seria equacionada por intermédio de um "pacto social” que contemplasse bons índices de competitividade, crédito acessível e políticas sociais cada vez mais abrangentes. Entretanto, alguns autores como Antunes (2006), Sampaio Jr. (2012), Amaral (2014), Luce (2013), Mota (2012), dentre outros, enxergam as políticas novodesenvolvimentistas como uma falácia, tendo em vista que o cenário macroeconômico ainda permanece atrelado a algumas práticas típicas do neoliberalismo, aviltando cada vez mais as condições de vida dos trabalhadores, enquanto o capital e a ordem se complementam, na mesma medida em que os muito pobres ingressam no mercado de consumo (SADER, 2013). Assim, apesar dos ganhos efetivos das classes menos favorecidas, alguns sinais de descontentamento com os níveis de emprego, corrupção endêmica e políticas públicas deficientes ficaram evidentes nas manifestações de junho de 2013 (MARICATO et. al., 2013), fato que atesta a fragilidade desse projeto Novo Desenvolvimentista, que no Brasil é atualmente encabeçado pelo Partido dos Trabalhadores (PT) e seus aliados. 
Apesar de utilizar um discurso antiimperialista e pós-neoliberal para angariar apoio eleitoral, os novos desenvolvimentistas, representados pelos governos progressistas que alcançaram o poder em vários países na América Latina não romperam com a lógica do capital transnacional. Segundo Mota, Amaral e Peruzzo:

\begin{abstract}
“(...) está em curso um processo de repolitização regressiva da política que se faz com os argumentos anti-imperialistas, porém, em defesa do nacional-capitalismo, cuja principal mediação não são reformas sociais com impacto na redistribuição de renda. A intervenção social dos governos progressistas, vale dizer, nesses países em que a idéia de progresso se vincula a processos de modernização, sem que se alterem os pilares das relações sociais capitalistas, se dá nas políticas compensatórias de enfrentamento da pobreza, feitas com o uso de novas pedagogias de concertação de classe”. (2012, p. 172, grifos do original)
\end{abstract}

Destacando que, embora o projeto Novo Desenvolvimentista seja apresentado como uma estratégia para beneficiar as classes dominadas através de governos avessos ao neoliberalismo, Sampaio Jr. (2012) assinala que tais enunciados não encontram respaldo na realidade. Segundo este autor, dissertando sobre a faceta conservadora deste novo modelo de desenvolvimento, em comparação ao velho desenvolvimentismo no Brasil, destaca:

\footnotetext{
"Ao transformar o Brasil em modelo, a perspectiva do novo desenvolvimentismo não passa de uma tosca apologia da ordem. A perspectiva do velho desenvolvimentismo é um esforço de mostrar a necessidade inescapável de "reformas estruturais" que desatem a dupla articulação responsável pelo caráter particularmente selvagem do capitalismo na periferia do sistema capitalista mundial. O neodesenvolvimentismo naturaliza a dupla articulação responsável pelo capitalismo dependente. Suas formulações ficam limitadas a elocubrações sobre a possibilidade de arquiteturas alternativas de política econômica para administrar as estruturas. A perspectiva desenvolvimentista supõe a presença de sujeitos políticos dispostos a enfrentar o imperialismo e o latifúndio. Os novos desenvolvimentistas são entusiastas do capital internacional, do agronegócio e dos negócios extrativistas. Defendem a estabilidade da ordem. Não alimentam de que seja possível e mesmo desejável mudanças qualitativas no curso da história. São entusiastas do status quo. Na sua visão de mundo, desenvolvimento e fim da história caminham de mãos dadas”. (p. 685, grifos do original)
}

Neste sentido, evidencia-se a face contraditória deste novo modelo de desenvolvimento. Para as massas dominadas, a utopia da justiça social é convertida em mero acesso ao consumo e ao crédito, ao passo que para as classes dominantes a ordem capitalista, incluindo todo o seu aparato ideológico e coercitivo, permanece praticamente inalterada em sua essência.

\title{
A questão social na atualidade e o "novo" capitalismo
}

\section{POLÊM!CA | Revista Eletronica da Uerj}


A questão social surgiu no século XIX, na Europa, e exigiu a formulação de políticas sociais em benefício da classe operária, que estavam em pobreza crescente, dando fim às instituições do Welfare State (FALEIROS, 2006). A atual questão social, porém, refere-se à ampliação do mercado de trabalho na sociedade capitalista, que agora se caracteriza pela sua degradação e desaparecimento de muitas categorias e postos de trabalho. Tal fenômeno ocorre quando o Estado passa a se retirar do campo social, com cortes sistemáticos de verbas de políticas públicas, terceirizações, privatizações etc.

Após o fim das formas de produção do capitalismo fordista e de seus empregos estáveis, essas condições foram transmutadas para outra dinâmica de acumulação, que enfatiza a competitividade e a qualidade em nível global. O processo de reestruturação produtiva, sobretudo após a década de 1970, inclui inovações tecnológicas e novas formas de gestão da força de trabalho, tendo como resultado um aumento considerável da produtividade e alterações nas formas de organização da produção. Dessa forma, “o sistema de metabolismo social do capital necessita cada vez menos do trabalho estável e cada vez mais das diversificadas formas de trabalho parcial ou part-time, terceirizado, dos trabalhadores hifenizados de que falou Huw Beyton, que se encontram em explosiva expansão em todo o mundo produtivo e de serviços (ANTUNES, 2011a, p. 175, grifos do autor).

Os índices de desemprego se tornam cada vez mais elevados em muitos países do mundo. Nos países subdesenvolvidos, a flexibilização das relações de trabalho contribuíram sobremaneira para o aumento do desemprego e do setor informal. A exigência de uma maior competitividade introduz estratégias de racionalização e de redução constante dos custos, trazendo graves consequências para os níveis de emprego. O trabalhador assalariado começou a conviver com a insegurança e as formas precárias de trabalho e de subcontratação, que passaram a ser incorporadas dentro das empresas. Os sindicatos revelam-se cada vez mais impotentes diante de tal contexto de intensa competitividade, uma vez que as empresas são forçadas a prover produtos de qualidade com preços cada vez mais baixos. Segundo Santana e Ramalho:

“(...) a situação atual aponta para um processo gradativo de precarização do trabalho e fragilização da organização coletiva dos trabalhadores. O movimento sindical passa pela dificuldade de lidar com situações de trabalho diante das quais políticas e estratégias de ação sindical parecem impotentes e incapazes de deter a destruição de direitos e de se relacionar com uma força de trabalho de características diversas daquela encontrada no pátio das grandes empresas [...] Durante muito tempo, foi a 
partir do trabalho que se propagaram movimentos de universalização de direitos para toda a sociedade [...] No caso brasileiro, os dilemas são ainda maiores, já que o processo de reestruturação produtiva chegou ao país sem que se tenha resolvido os problemas sociais mais básicos.” (2009, p. 53)

O modelo toyotista, originado no Japão, tornou-se referência como exemplo de um novo paradigma produtivo que estaria ultrapassando o fordismo. A forma de organização de algumas empresas japonesas era alicerçada em um trabalho cooperativo, com ausência de demarcação das tarefas, a partir dos postos de trabalho. O trabalhador dessas empresas japonesas é o exemplo da polivalência e da multifuncionalidade. As qualificações exigidas nesse novo modelo produtivo contrastariam com a lógica do taylorismo, na medida em que se exige do trabalhador a capacidade de pensar, ter iniciativa e decidir.

Sendo assim, a própria exigência de novas qualificações coloca em questão a maneira de se conceber a noção de qualificação permanente para manter-se empregado, surgindo daí o conceito de empregabilidade, que é definido como a capacidade de mão de obra de se manter empregada ou de encontrar um novo emprego quando demitida, ou seja, de se tornar indefinidamente empregável.

No tocante à realização prática destas noções, destaca-se a integração em fluxo contínuo das etapas, a circulação permanente do produto em transformação, redução de estoques com a implementação do just in time (controle do estoque), sistema kan-ban (controle de produção) e organização celular da manufatura, predominando a ideia da focalização das atividades da empresa em produtos e tarefas que garantam maior competitividade e lucratividade, deixando outras atividades para firmas terceiras.

No caso brasileiro, a partir de 2004, houve uma expansão média anual da renda per capita de 3,3\%, subindo 14,8\% a participação do rendimento do trabalho na renda nacional entre 2004 e 2010. Tal cenário projetou sobre a classe trabalhadora um ímpeto de otimismo em contraposição às décadas anteriores, visto que "o principal aspecto das mudanças sociais observadas até a década de 1980 no Brasil foi o vigor da aceleração industrial” (POCHMANN, 2013, p. 147). Em seguida, este mesmo autor destaca a geração significante de postos de trabalho nos governos Lula e Dilma, muito embora ressalte que 95\% das vagas abertas correspondiam a uma faixa de renumeração mensal de até 1,5 salários mínimo. A partir daí surge a "nova classe média”, também conhecida como “Classe C”, que é composta de trabalhadores, provenientes de estratos desfavorecidos da população brasileira, que tiveram

\section{POLÊM!CA | Revista Eleroronica da Uej}


a oportunidade de ascender socialmente a partir do incremento do emprego formal, após a assunção do Partido dos Trabalhadores à Presidência da República.

Todavia, apesar do período dos governos Lula e Dilma serem caracterizados pelo rompimento com o neoliberalismo e o retorno à intervenção do Estado na economia, cumprindo seu papel redistributivo, cabe salientar que este Novo Desenvolvimentismo não coloca em questão aspectos clássicos relativos às condições de trabalho e qualidade de vida dos trabalhadores. Assim, o crescimento econômico e aumento dos níveis de emprego não garantem ao trabalhador satisfação em seu cotidiano, sobretudo quando se considera que o Brasil compete com as “economias emergentes” de países como a China e a Índia, que dispõem de uma força de trabalho muito maior e disposta a trabalhar sob condições precárias de super exploração, produzindo uma mais-valia relativa de grande impacto econômico. Entretanto, tal situação já era diagnosticada por Karl Marx no século XIX em O Capital, conforme segue:

(...) dentro do sistema capitalista, todos os métodos para levar a produtividade do trabalho coletivo são aplicados às custas do trabalhador individual; todos os meios para desenvolver a produção redundam em meios de dominar e explorar o produtor, mutilam o trabalhador, reduzindo-o a um fragmento de ser humano, degradam-no à categoria de peça de máquina, destroem o conteúdo de seu trabalho transformado em tormento; tornam-lhe estranhas as potências intelectuais do processo de trabalho [...] na medida em que se acumula o capital, tem de piorar a situação do trabalhador, suba ou desça sua remuneração. (IANNI, 1992, p.129-130)

Nesses termos é importante perceber que o recente crescimento econômico vivenciado pelo Brasil no início do século XXI, que o projetou de um país subdesenvolvido para um país “emergente” e participante do clube dos BRICS (Brasil, Rússia, Índia, China e África do Sul), não significa necessariamente que as nossas políticas sociais tenham progredido em uma direção que contesta o atual modelo de acumulação capitalista. Pelo contrário, várias pesquisas empíricas indicam que essa atual fase de crescimento veio acompanhada de uma exploração cada vez mais intensa de nossa força de trabalho (Cf. ANTUNES, 2006, 2011b; DAL ROSSO, 2008; LUCE, 2013).

Santos (2012) observa que se verificou, no governo Lula, um aumento da precarização e da flexibilidade do emprego e, por conseguinte, da exploração do trabalho, incluindo a terceirização do trabalho, fenômeno perverso para o "barateamento" de mão de obra e a negação de direitos sociais. Dessa forma, pode-se apreender que o ideário “neodesenvolvimentista” opera pela via do "transformismo”, na perspectiva da mais antiga 
obsessão do capitalismo, que seria “'diluir’ ideologicamente (e, por isso, de forma aparente) os antagonismos entre as classes sociais” (p. 444).

Os novos trabalhadores da era lulista seriam o precariado brasileiro, recentemente saído do pauperismo e representado por trabalhadores jovens, não qualificados ou semiqualificados, precarizados e inseridos em relações trabalhistas com frágil ou inexistente organização coletiva. É a partir dessa massa que o PT - anteriormente um partido ligado aos intelectuais de esquerda, estudantes universitários, funcionários públicos etc. - irá construir sua nova base eleitoral. Segundo Alves (2015):

\footnotetext{
Na verdade, a loucura da forma-mercadoria impulsionada na era do novo desenvolvimentismo se introjetou na subjetividade - mente e corpo - do homemque-trabalha, adoecendo, nos locais de trabalho reestruturados, personalidades singulares expostas à insalubridade do modo de vida just-in-time. Enfim, cresceram os adoecimentos laborais, principalmente transtornos mentais, nas mais diversas camadas sociais do proletariado brasileiro - principalmente nas camadas assalariadas médias expostas diretamente ao modo de vida just-in-time. É o que explica, nos últimos dez anos, por exemplo, os lucros exorbitantes da indústria farmacêutica com seus medicamentos "tarja preta".

Esta é, portanto, uma dimensão oculta da precarização do trabalho no Brasil. Apesar dos inegáveis méritos nas políticas distributivistas para as camadas pobres da população brasileira, o novo desenvolvimentismo como novo choque de capitalismo na terceira modernidade brasileira, promoveu a precarização existencial que, em si $e$ para si, como precarização do trabalho, é o lado perverso da precarização do sujeito humano como sujeito capaz de práxis histórica. (p. 11)
}

Não obstante a condição do trabalhador tenha se tornado cada vez mais aviltante, é também importante ressaltar que o Novo Desenvolvimentismo não logrou êxito em diminuir a concentração de riqueza na América Latina, mesmo considerando que os incentivos de programas de transferência de renda, que conseguiram inserir milhares de famílias no mercado consumidor, uma vez que essas políticas tendem a não interferir na origem das desigualdades. O continente ainda continua com as maiores taxas de desigualdades sociais do planeta. No Brasil, os $10 \%$ mais ricos possuem quase $75 \%$ da riqueza nacional, enquanto os mais pobres ficam apenas com os restantes 25\%. Cenário semelhante ocorre em outros países da região. No que tange à política de expansão do crédito, cabe salientar que, segundo a Confederação Nacional do Comércio (CNC), 57,4\% da população brasileira tem alguma dívida. Destes, 70,85\% estão devendo a cartões de crédito (MOTA; AMARAL; PERUZZO, 2012).

\section{POLÊM!CA | Revista Eletronica da verj}




\section{Considerações Finais}

Levando em conta que as políticas sociais deveriam ter como consequência a melhoria das políticas sociais universais e, por consequência, o padrão de vida da classe trabalhadora, então se pode inferir que elas podem ter a sua principal meta comprometida na medida em que o Novo Desenvolvimentismo incita a degradação das condições de vida da classe trabalhadora, tendo como argumento a necessidade do aumento contínuo da competitividade em meio a uma crise econômica global. Dessa forma, este "novo" modelo de desenvolvimento, ao invés de propor mudanças estruturais que favoreçam melhor condição de vida à classe trabalhadora, como almejava o antigo desenvolvimentismo, finda por transformar-se em mera falácia demagógica a serviço do capitalismo globalizado.

Embora a América Latina seja atualmente governada por partidos de orientação progressista, que criticam os cânones neoliberais, as empresas transnacionais degradam o meio ambiente utilizando o argumento das vantagens do crescimento econômico per se, os direitos trabalhistas enfrentam contínuas ameaças e as políticas públicas tendem a centrar-se no enfrentamento da pobreza, fazendo com que ao Estado caiba a tarefa de apoiar a ideologia do empreendedorismo, dos negócios, com vistas a acumular um capital social robusto para enfrentar os desafios da competitividade global, aceitando a permanência das desigualdades sociais como uma realidade imutável, não obstante o discurso pós-neoliberal continue a difundir-se na retórica de tais agremiações políticas.

\section{Referências}

ALVES, Giovanni. Novo desenvolvimentismo e precarização do trabalho no Brasil - Parte III. Disponível em: <http://blogdaboitempo.com.br/2013/09/23/novo desenvolvimentismo-e-precarizacao-do-trabalho-no-brasilparte-iii/>. Acesso em: 14 abr. 2015.

AMARAL, Angela Santana. Configurações Contemporâneas dos conflitos classistas: experiências brasileiras no contexto neodesenvolvimentista. Disponível em:

<http://actacientifica.servicioit.cl/biblioteca/gt/GT18/GT18_SantanaDoAmaral.pdf>. Acesso em: 24 abr. 2014.

ANTUNES, Ricardo. (org.). Riqueza e miséria do trabalho no Brasil. São Paulo: Boitempo, 2006.

Adeus ao trabalho?: ensaio sobre as metamorfoses e a centralidade do mundo do trabalho. 15 ed. São Paulo: Cortez, 2011a.

Continente do labor. São Paulo, SP: Boitempo, 2011b.

BRAND, Ulrich; SECKLER, Nicola (orgs.). Diante da crise global: horizontes do pós-neoliberalismo. Rio de Janeiro: UERJ, 2010.

\section{POLÊM!CA | Revista Eletronica da Ueji}


BRESSER-PEREIRA, Luiz Carlos. Do antigo ao novo desenvolvimentismo na América Latina. Disponível em: <http://www.bresserpereira.org.br/papers/2012/12.Do_antigo_ao_novo_desenvolvimentismo.pdf>. Acesso em: 28 abr. 2014.

BOURDIEU, Pierre. Contrafogos: táticas para enfrentar a invasão neoliberal. Rio de Janeiro: Jorge Zahar, 1998.

CASTELO BRANCO, Rodrigo. O novo-desenvolvimentismo e a decadência ideológica do estruturalismo latinoamericano. Oikos, Rio de Janeiro, v. 8, n. 1, 2009.

DAL ROSSO, Sadi. Mais trabalho!: a intensificação do labor na sociedade contemporânea. São Paulo: Boitempo, 2008.

FALEIROS, Vicente de Paula. O que é política social. São Paulo: Brasiliense, 2006.

IANNI, Octavio (org). Karl Marx. 7 ed. São Paulo: Ática, 1992. (Coleção Grandes Cientistas Sociais).

LUCE, Mathias Seibel. Brasil: nova classe média ou novas formas de superexploração da classe trabalhadora? Trab. Educ. Saúde, Rio de Janeiro, v. 11 n.1, p. 169-190, jan./abr. 2013.

MARICATO, Ermínia et. al. Cidades rebeldes: Passe Livre e as manifestações que tomaram as ruas do Brasil. São Paulo: Boitempo, 2013.

MOTA, Ana Elizabete; AMARAL, Ângela Santana; PERUZZO, Juliane Feix. O novo desenvolvimentismo e as políticas sociais na América Latina. In: MOTA, Ana Elizabete (org.). Desenvolvimentismo e construção de hegemonia: crescimento econômico e reprodução da desigualdade. São Paulo: Cortez, 2012.

SAMPAIO JR., Plínio de Arruda. Desenvolvimentismo e neodesenvolvimentismo: tragédia e farsa. Serv. Soc. Soc., São Paulo, n. 112, p. 672-688, out./dez. 2012.

SANTANA, Marco Aurélio; RAMALHO, José Ricardo. Sociologia do trabalho no mundo contemporâneo. 2 ed. Rio de Janeiro: Jorge Zahar, 2009.

SANTOS, Josiane Soares. Particularidades da "questão social” no Brasil: mediações para seu debate na "era” Lula da Silva. Serv. Soc. Soc., São Paulo, n. 111, p. 430-449, jul./set. 2012.

SOUZA, Herbert José. Como se faz análise de conjuntura. 34 ed. Petrópolis, RJ: Vozes, 2014.

POCHMANN, Márcio. Políticas públicas e situação social na primeira década do século XXI. In: SADER, Emir (org.). Lula e Dilma: 10 anos de governos pós-neoliberais no Brasil. São Paulo: Boitempo, 2013.

Recebido em: 10/02/2015.

Aceito em: 27/05/2015. 